\title{
AS POLÍTICAS AMBIENTAIS E O PLANEJAMENTO DA PAISAGEM: ENTRE O IDEAL E O REAL
}

MARIA DA GLÓRIA LANCI DA SILVA 


\section{RESUMO}

Este texto tem como objetivo demonstrar a relação entre a proteção ao meio ambiente preconizada pelo poder público e a realidade brasileira, em especial no Estado de São Paulo.

Através de três exemplos (a rodovia Fernão Dias, a rodovia doSol e a represa Billings), são comentados os seguintes aspectos:

- o arcabouço legislativo e a postura oficial do Estado frente a problemas ambientais emergentes;

- a prática do planejamento paisagístico diante das restrições legais e da falta de referências projetuais;

- a correlação entre a produção da paisagem e o ideário ambientalista vigente.

\section{ABSTRACT}

$T$ his text focuses on the relationship between the actions about environmental protection proposed by the State in three different situations - Fernão Dias Road, Sol Road and Billings Dam.

Three main questions are commented:

- the legislative framework and the State official position in relation with the emergent environmental problems;

- the practice of the landscape planning in the face of legal restrictions and the lack of design references;

- the relationship between the landscape changes and the actual environmental ideology. 


\section{INTRODUÇÃO}

A

paisagem caracteriza-se principalmente por um eterno movimento de produção e reprodução; o conjunto de sua estrutura e objetos é feito, "desmanchado" e novamente refeito por força das atividades humanas e de suas ideologias. "As formas da paisagem são resultados do equilíbrio entre múltiplas forças e processos temporais e espaciais. Em certa medida, a paisagem é um reflexo da visão social do sistema produtivo e transformase, ou desaparece, sempre que as teorias, filosofias e necessidades que a criaram não são mais reais ou auto-evidentes'."

Uma das mudanças mais sensíveis neste processo deveu-se à conscientização ecológica, no início da década de 70. A questão ambiental assumiu importância mundial na ocasião da Conferência das Nações Unidas sobre o Meio Ambiente, realizada em Estocolmo, no ano de 1972. Pela primeira vez temas como a poluição do ar e o efeito estufa, que são decorrentes da industrialização, da explosão demográfica e da miséria de muitos países, tomaram proporçōes globais e colocou-se em xeque os modelos de urbanização, as tecnologias, a exploração de recursos, o capitalismo "selvagem" e o próprio "modus vivendi" do homem moderno. Os movimentos que se seguiram, as políticas implantadas, a nova forma de ver a cidade e o meio ambiente contribuíram para conceber um novo comportamento social e conseqüentemente uma nova ordenação do espaço.

No Brasil os reflexos dessa postura resultaram na criação de leis específicas, novas instâncias governamentais (como a Secretaria Especial do Meio Ambiente, em 1973), organizações civis e partidárias (o Partido Verde surge na década de 80 ). A repercussão deu-se em diversos segmentos da sociedade, principalmente entre a classe considerada como formadora de opinião. Incentivada e divulgada intensamente pela mídia, a ecologia atinge seu "auge" no país quando este sedia a segunda Conferência das Nações Unidas, a ECO'92, realizada no Rio de Janeiro. 
Nos últimos 20 anos, o movimento ambientalista como força política cresceu em todo o mundo, sofreu algumas derrotas, repensou certas atitudes, e hoje constitui-se de adeptos que vão desde "grupos comunitários" a grandes empresas multinacionais que gerenciam ou financiam programas de conservação ambiental².

\section{A POLÍTICA AMBIENTAL BRASILEIRA}

A primeira lei de caráter ambientalista foi o que é atualmente conhecido como código florestal. Sua primeira versão é de 1934 e a última de 1989. Esta lei, ainda em vigor, traçou os parâmetros de proteção exclusivamente para as formações florestais, com preocupações meramente preservacionistas ${ }^{3}$.

A política nacional do meio ambiente foi consolidada com a Lei 6.938 , de 31 de agosto de 1981, atribuindo à União estabelecer normas sobre a proteção do meio ambiente e os instrumentos para tal, bem como a criação do Conama (Conselho Nacional do Meio Ambiente). No mesmo ano a Lei 6.902, de 27 de abril de 1981, havia estabelecido normas para a criação de APAs (Áreas de Proteção Ambiental) e Estações Ecológicas.

A política nacional de meio ambiente tem como instrumentos: oAIA - Avaliaçãode Impacto Ambiental; o zoneamento ambiental e o licenciamento ambiental, composto pelas licença prévia, licença de instalação e licença de operação. $O$ zoneamento ambiental deveria préceder o AIA, mas a resolução 001/86 do Conama inverteu essa prioridade, ao condicionarolicenciamento das atividades ao EIA/RIMA - Estudo e Relatório de Impacto Ambiental.

Pela resolução, torna-se obrigatória a elaboração e apresentação do EIA Estudo de Impacto Ambiental e respectivo RIMA (Relatório de Impacto Ambiental), para o licenciamento de atividades consideradas modificadoras do meio ambiente, ou seja, "qualquer alteração das propriedades físicas, químicas e biológicas do meio ambiente, causada por qualquer forma de 
matéria ou energia resultante das atividades humanas que, direta ou indiretamente, afetem:

I. A saúde, a segurança e o bem-estar da população;

II. as atividades sociais e econômicas;

III. a biota;

IV. as condições estéticas e sanitárias do meio ambiente;

V. a qualidade dos recursos ambientais ${ }^{\prime 4}$.

O EIA é exigido para atividades como: extração de minério, implantação de estradas de rodagem e ferrovias, terminais de petróleo e produtos químicos, troncos coletores e emissários de esgotos sanitários, obras hidráulicas para exploração de recursos hídricos, aterros sanitários, distritos industriais, projetos urbanísticos com área acima de 100 ha ou localizadas em áreas protegidas por legislação específica.

O Estudo de Impacto Ambiental difere do RIMA por ser o texto integral de todas as atividades referentes à elaboração do estudo (literatura científica e legal, levantamentos de campo, análises, etc.) e mais a conclusão do trabalho. O RIMA se refere apenas às conclusões do EIA e é elaborado como um resumo, ficando à disposição para consulta pública, visto que muitas vezes o EIA pode compreender vários volumes, pela complexidade de alguns trabalhos.

\section{A CONDUÇÃO DA POLÍTICA AMBIENTAL NO ESTADO DE SÃO PAULO}

No Estado de São Paulo a SMA (Secretaria do Meio Ambiente)

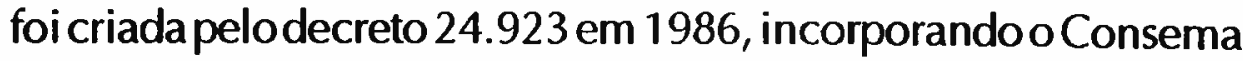
(Conselho Estadual do Meio Ambiente), existente desde 1983, e órgãos como os Institutos Geológico, Florestal e o de Botânica. A possibilidade oferecida pela legislação de ampliar a área de 
proteção ambiental do Estado resultou, somente entre 1981 e 1988, na criação de 21 APAs (sendo 15 estaduais e 6 municipais) e 20 estacões ecológicas. Na região metropolitana de São Paulo, por exemplo, surgiram a APA da várzea do Tietê, a APA de Cajamar, o Parque Ecológico do Tietê e o Parque Nascentes do Tietê.

Outro instrumento importante na condução da política ambiental para o Estado de São Paulo é o Estudo de Impacto Ambiental (EIA), que permite o monitoramento, pela SMA, do uso e ocupação do solo mesmo em áreas não protegidas. Para a Secretaria do Meio Ambiente do Estado de São Paulo, o Estudo de Impacto Ambiental deve ser elaborado obedecendo o seguinte roteiro ${ }^{5}$ :

\section{Informações Gerais}

- Identificação e localização;

- histórico;

- sintese dos objetivos;

- justificativa do empreendimento.

2. Caracterização do Empreendimento

- Plano de implantação e operação.

3. Área de Influência

- Limites geográficos;

- justificativa de acordo com a abrangência dos impactos.

\section{Diagnóstico Ambiental}

\subsection{Meio físico}

- Clima e condições meteorológicas;

- qualidade do ar;

- níveis de ruído; 
- geologia;

- geomorfologia;

- solos;

- recursos hídricos.

4.2. Meio biológico

- Ecossistemas terrestres;

- ecossistemas aquáticos;

- ecossistemas de transição.

4.3. Meio antrópico

- Dinâmica populacional;

- uso e ocupação do solo;

- nível de vida;

- estrutura produtiva e de serviços;

- organização social.

5. Análise dos Impactos Ambientais

- Impactos diretos e indiretos;

- impactos benéficos e adversos;

- impactos temporários, permanentes e cíclicos;

- impactos imediatos e a médio e longo prazos;

- impactos reversíveis e irreversíveis;

- impactos locais, regionais e estratégicos.

6. Proposição de Medidas Mitigadoras

7. Programa de Acompanhamento e Monitoramento dos Impactos Ambientais 
Estes itens devem constar obrigatoriamente do EIA, constituindo, portanto, um método para a sua execução. $O$ roteiro é abrangente, e a SMA exige por parte do empreendedor o monitoramento de suas ações, antes e durante a implantação do projeto, colocando-se como agente fiscalizador desse processo.

Para o controle das várias etapas do processo de aprovação do EIA e implantação da atividade, a SMA concede três licenças:

- A licença prévia, na aprovação do EIA/RIMA;

- a licença de instalação, na aprovação do projeto e para o início das obras;

- a licença de operação, após vistoria, para o funcionamento.

Após a licença de operação cessa a ação da Secretaria e o processo é então arquivado.

O que não fica muito claro nessa estrutura é a relação entre a metodologia adotada e as escalas de abrangência do estudo. Via de regra, ela é válida tanto para um loteamento turístico de 100 ha numa área urbana, quanto para a construção de uma represa em área rural. Evidentemente as questões não são as mesmas para os dois exemplos e, embora a organização institucional do Estado englobe outros agentes fiscalizadores, é a SMA que detém os instrumentos necessários para a avaliação de impactos ambientais.

Sob este ponto de vista, elaborar regras tão específicas e ao mesmo tempo tão abrangentes torna-se tarefa inócua sem o respaldo da fiscalização in loco, visto que o objetivo primeiro desta normatização é controlar a intervenção no meio ambiente, evitando ou minimizando possíveis impactos. 
Há que se ressaltar um ponto extremamente negativo: a duração da tramitação de alguns processos na secretaria chega a ser superior a um ano. Esta atuação extremamente lenta torna inviável o aprimoramento da discussão tanto do projeto em si (vista a defazagem de dados), quanto da política ambiental como um todo. Quando se trata de obras de grande vulto, empreendidas pelo próprio governo, perde-se não só os recursos financeiros já comprometidos como a oportunidade de reverter o conhecimento técnico adquirido para o benefício público.

\section{A PRÁTICA DE INTERVENÇÕES NO AMBIENTE}

Um dos exemplos que podemos citar para demonstrar os conflitos entre governo e sociedade civil é o caso da duplicação da rodovia Fernão Dias, que liga São Paulo a Belo Horizonte, um projeto antigo dos governos dos Estados de São Paulo e Minas Gerais. As péssimas condições de tráfego e o intenso movimento a fazem uma das rodovias interestaduais mais perigosas do Brasil.

A duplicação de estradas exige estudo de impacto ambiental. No caso da Fernão Dias, foi realizado um consórcio entre o DNER (Departamento Nacional de Estradas de Rodagem) e os DERs (Departamento de Estradas de Rodagem) de São Paulo e Minas Gerais, resultando em um único trabalho de avaliação de impactos, feito por uma empresa sediada em São Paulo. Na fase de projeto caberia a cada Estado elaborar seu próprio estudo.

No segmento paulista da estrada surgem prontamente duas agravantes: a travessia pela Serra da Cantareira, área preservada por legislação federal e estadual, e a travessia pela área de proteção aos mananciais da bacia do rio Juqueri, que abastece a região metropolitana através do sistema cantareira (Figura 1). 





Os primeiros estudos se concentraram em avaliar alternativas de traçado para a duplicação no trecho da Serra da Cantareira, evitando a execução de uma obra que certamente seria onerosa e tecnicamente difícil, além de causar impactos ao ecossistema. As alternativas estudadas - Oeste 1, Oeste 2 e Leste - mostraramse inviáveis operacionalmente: seria necessário um desvio muito extenso que, por esta razão, não justificaria a mudança da rota de tráfego, cuja maior carga concentra-se entre São Paulo e Atibaia. Além disso, implicaria em duas novas intersecções de grande porte, na Marginal do Tietê e na rodovia Dom Pedro I. Estas alternativas também provocariam impactos ambientais, principalmente a alternativa Leste, que passa por uma área florestada e de topografia difícil. Resumindo, o custo financeiro e ambiental era muito alto para poucos benefícios. Desta forma, o Estudo de Impacto Ambiental procurou viabilizar a duplicação da rodovia ao lado da pista já existente, realizando avaliações sobre os possíveis impactos e as medidas mitigadoras pertinentes.

Um ano depois de iniciado, o EIA foi rapidamente aprovado pela secretaria e o governo do Estado já tinha em mãos boa parte dos recursos do financiamento externo obtido junto ao BID - Banco Interamericano de Desenvolvimento. Mas, antes mesmo de ser concedida a licença prévia, o Ministério Público aprovou ação liminar contra o Estudo de Impacto Ambiental, num processo impetrado por ambientalistas e organizações civis, paralisando o projeto. Os ambiental istas alegavam que a duplicação na Serra da Cantareira, implicando no corte de vegetação nativa, não poderia ser feita por tratar-se de área de preservação.

Neste caso, houve um deslocamento da discussão. A questão pertinente seria inquirir o governo quanto à condução das obras e às medidas mitigadoras de impactos, pois o problema quanto às alternativas de traçado já fora superado através do trabalho anterior ao EIA/RIMA.

Os critérios técnicos em favor de um projeto, que aparentemente não tinha objeções óbvias, não foram argumentos eficientes para os ambientalistas autores da ação liminar. Para estes a obra 
tinha um caráter "político oportunista", sem justificativas sociais, econômicas ou até mesmo ambientais. Esta imagem veiculada pelos ambientalistas para a população leiga que, não tendo o acesso direto às informações, acaba por tomar partido de uma crítica oposicionista fácil, prejudica o próprio conceito ecológico de desenvolvimento sustentado, pois não é possível discutir obras desse porte mediante argumentos como a metragem quadrada de árvores cortadas em uma área protegida como a Serra da Cantareira e não questionar, por exemplo, o perigo trazido pelos acidentes ocorridos com cargas tóxicas ou inflamáveis, devido às precárias condições da estrada, ocasionando uma seqüência de impactos no ecossistema que se prolongam por muito mais tempo.

Não se trata de atenuar os problemas ou desconsiderá-los; tudo deve entrar em pauta, mas é necessário uma abordagem metodológica, onde a visão mais abrangente inclui a hierarquização de prioridades em nível não só local como regional. A preservação não é instrumento apenas para assegurar reservas florestais intactas, mas também uma estratégia para a reserva de recursos naturais a serem explorados pelo homem.

Um outro episódio ficou bastante conhecido pela polêmica que causou: o Estudo de Impacto Ambiental da rodovia do Sol, que seria uma auto-estrada ligando a cidade de Jacareí ao porto de São Sebastião. A estrada cortaria a Serra do Mar, protegida por lei, um dos últimos ecossistemas em razoável estado de preservação, não só no Estado de São Paulo, como no Brasil (Figura 2).

O projeto justificava-se por fatores econômicos e inseria-se dentro de um plano estadual de transportes, onde a rodovia seria o escoadouro da produção agrícola de grande parte do interior paulista. Ligada a um sistema de "containers" nos portos de São Sebastião e Santos, reverteria também em um transporte mais seguro das cargas perigosas.

Foi realizado o Estudo de Impacto Ambiental e submetido à comunidade. Na época foi uma discussão bastante acirrada 
entre o podèr público e a população, que não queria a construção da estrada, intermediada pela forte influência de grupos preservacionistas. O estudo foi recusado e o projeto engavetado.

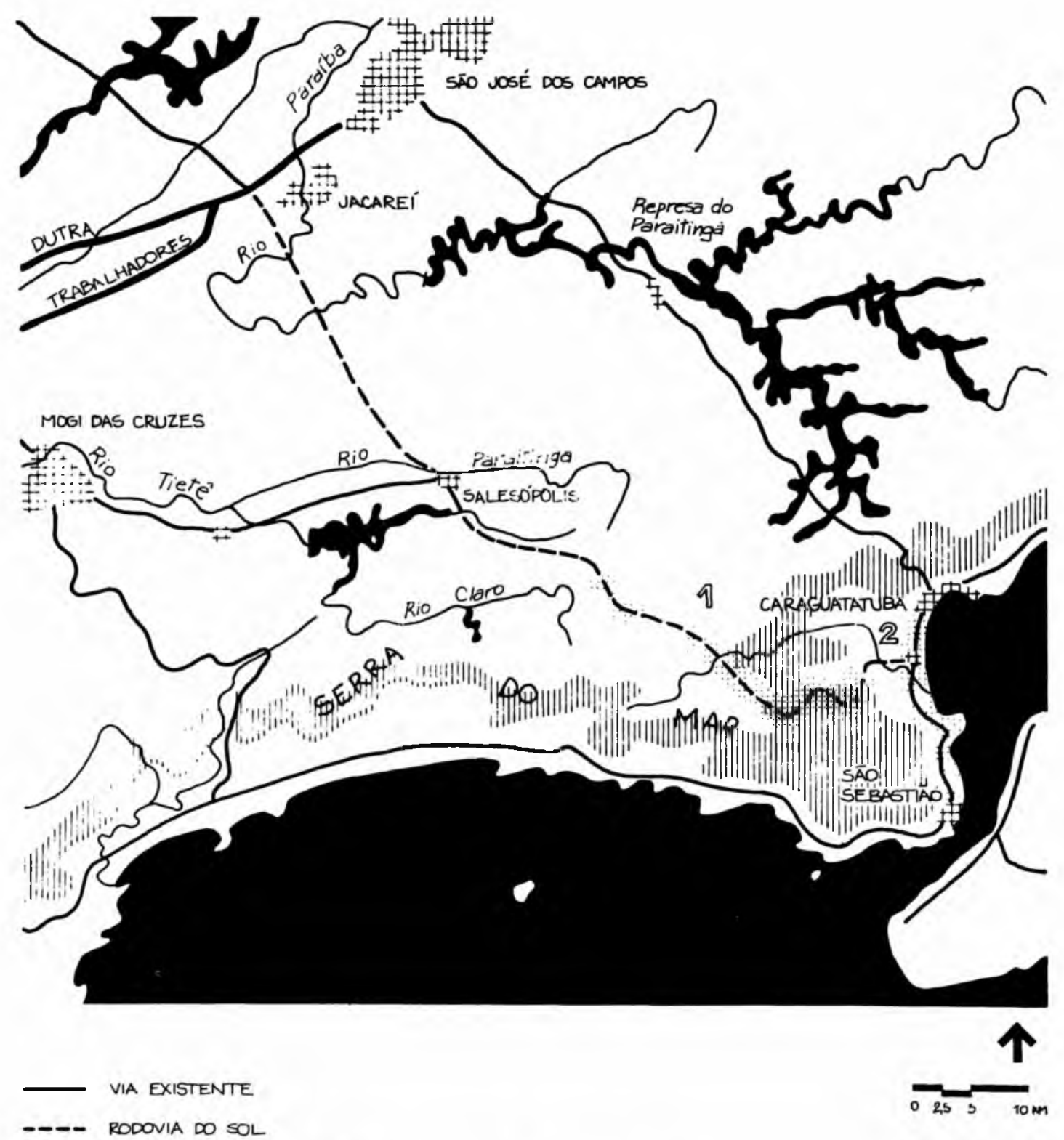

ÁREAS DE MAIOR IMPACTO

D FAPDUE ESTADUAL DA SERRA DO MMR - ALTERACJO DO ECOSSISTEMA

8 FANXA LITORÂNEA - EXPANSAO JREANA 
Um ex-diretor da Cetesb (Companhia de Tecnologia de Saneamento Ambiental), em um seminário internacional realizado há pouco mais de dois anos, defende: “... a estrada poderia provocar a criação de uma estrutura de administração e fiscalização que propiciasse também uma espécie de defesa do Parque Estadual da Serra do Mar. Essa medida, se fosse bem projetada e executada, poderia ser altamente positiva..." ${ }^{\prime S}$ Seus argumentos são plausíveis e, independente de suas posições ideológicas, não há dúvidas de que realçam o caráter sóciopolítico da questão.

Por outro lado, os problemas ambientais neste caso são bastante graves, pois trata-se da abertura de uma nova estrada, o que é muito diferente da duplicação de uma já existente, como no caso da Fernão Dias. Os impactos não são apenas diretos e locais, mas repercutem em uma ampla região, reorganizandoa de modo totalmente diverso. O ecossistema sofre com as ações não só imediatas (retirada da cobertura vegetal, recondução da drenagem natural e modificação do perfil topográfico), como também a longo prazo, com a demanda de serviços e infraestrutura pelo próprio processo de expansão urbana ${ }^{7}$

Em se considerando a opinião totalmente divergente de um grupo e de outro, ficou a sensação de "pecado" que envolveu o público ao se discutir a construção de uma estrada passando pela Serra do Mar. Este aspecto é negativo pois não possibilita a discussão técnica e resume a questão a um mero jogo de forças políticas. Por esse motivo é importante haver um consenso entre o parecer dos técnicos e as posturas políticas. Um Estudo de Impacto Ambiental não pode ser submetido à audiência pública sem estar firmemente embasado em todas as questões, sejam elas de cunho científico ou de cunho social, assim como a população não pode avaliá-lo sem o devido conhecimento de causa. Além disso, corre-se o risco de transformar um instrumento para licenciamento de atividades interferentes no meio, que é o objetivo do EIA, em "bandeira" para reivindicações que só poderiam ser satisfeitas com um plano macrorregional, o que fica evidente em relação à rodovia do Sol. 
Recentemente, mais uma divergência foi protagonizada pelos mesmos atores no recente caso da represa Billings, na zona sul de São Paulo. A represa é um reservatório de abastecimento de água para boa parte da região metropolitana, a mais populosa. Também é fornecedora de água doce para importantes indústrias de Cubatão, que contam também com a usina Henry Borden para produção de energia elétrica que, por sua vez, também utiliza água da Billings (Figura 3).

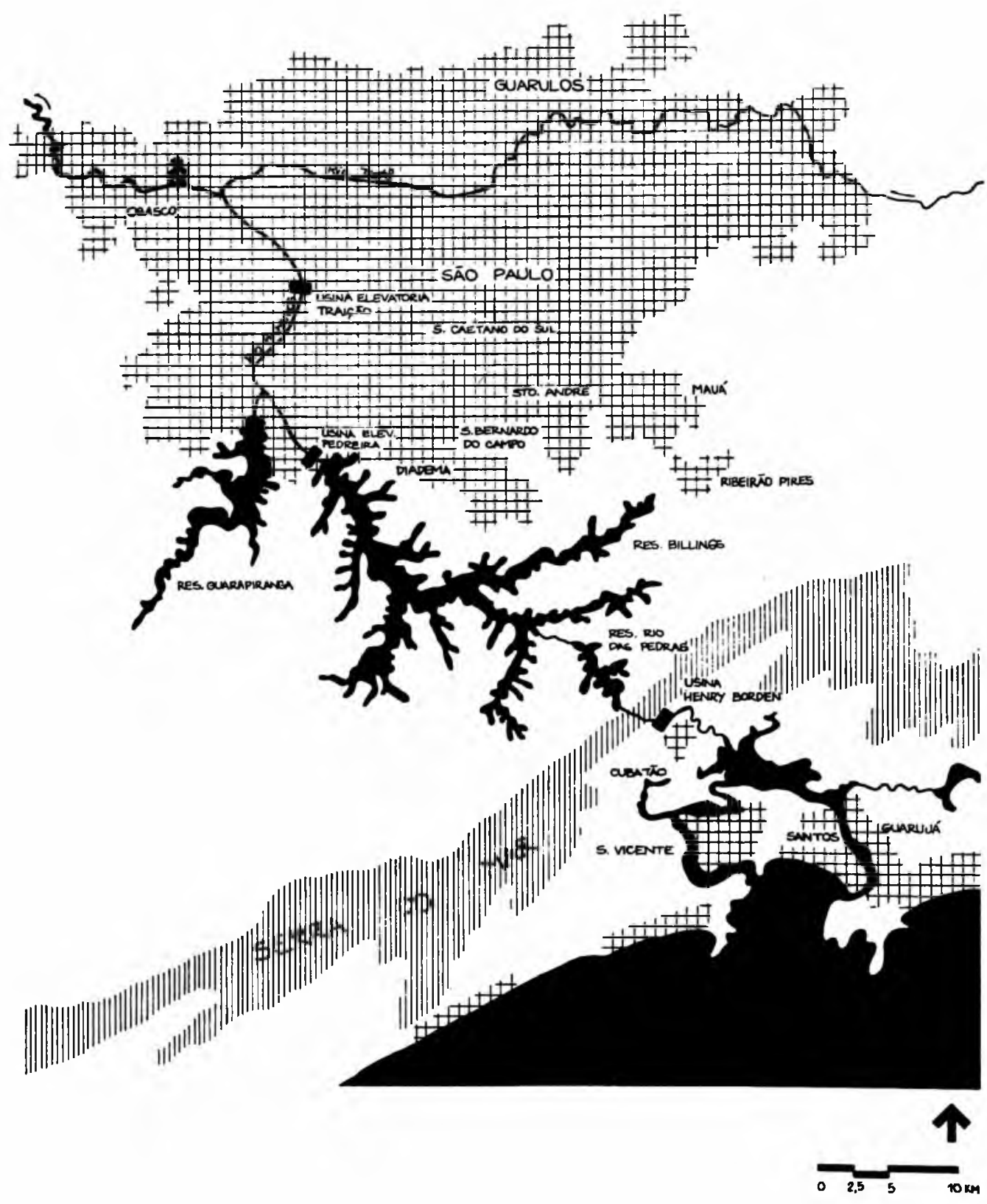


O rio Pinheiros, que teve seu curso invertido para aumentar a vazão da represa, apresenta altos níveis de poluição. Para não contaminar o manancial, em 1992 o bombeamento de suas águas foi suspenso. Mas o nível da Billings caiu muito e o Consema sugeriu ao governo estadual que interrompesse a descarga de água para Cubatão. As indústrias entraram em colapso, pressionaram o governo e este voltou atrás, retomando também o bombeamento de água do rio Pinheiros (Figura 4).
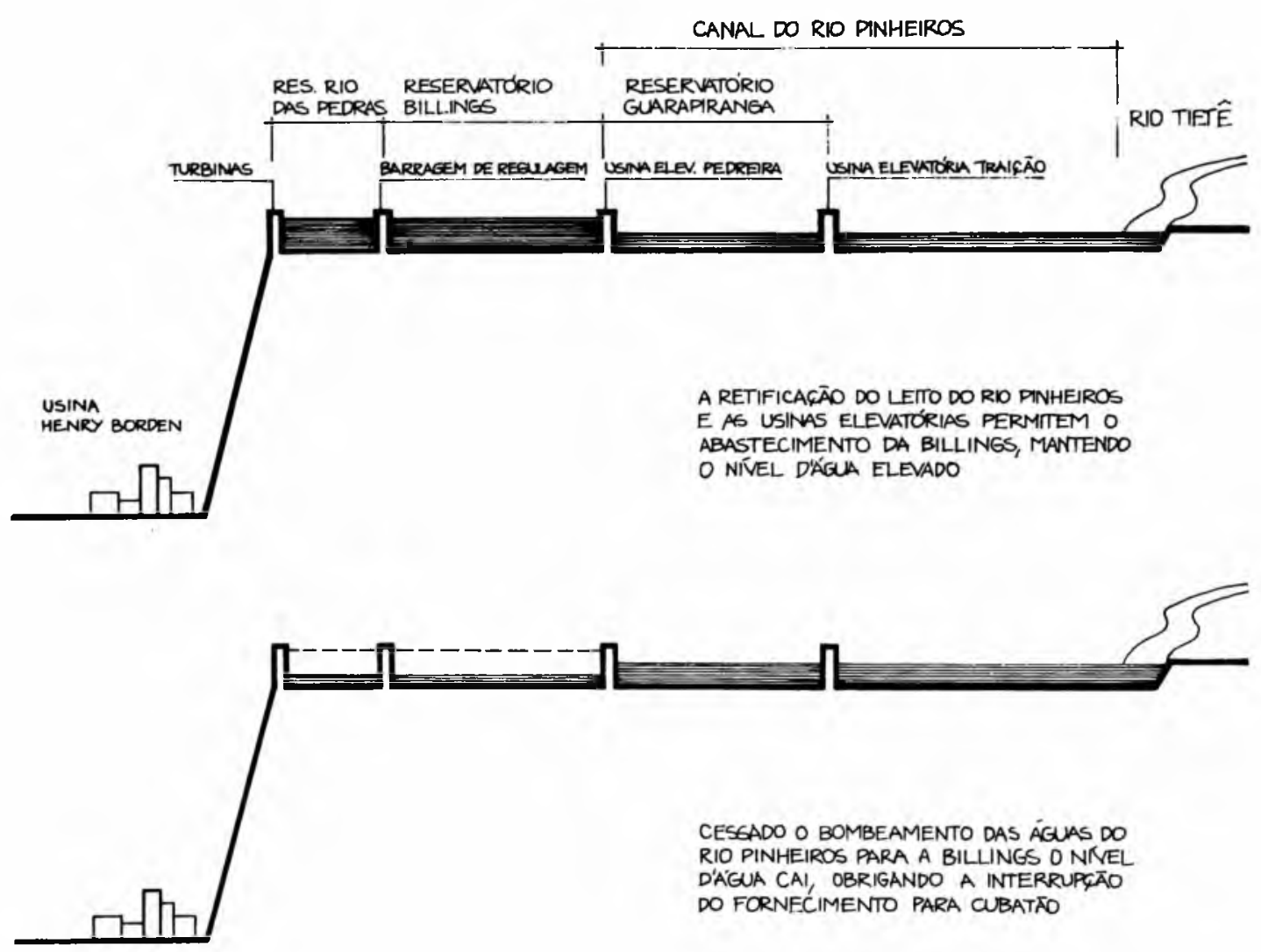
A partir daí criou-se o conflito entre o Estado, os ambientalistas, as prefeituras e a população em geral. De um lado, um pólo industrial que não pode parar, de outro, o risco imediato à saúde pública e a escassez de água para consumo. Ironicamente, a principal fornecedora de cloro para a Sabesp (Companhia de Saneamento Básico do Estado de São Paulo) está sediada em Cubatão. Um verdadeiro dilema ambiental e sócioeconômico, onde o governo está em uma posição onde qualquer decisão é arbitrária.

O complexo sistema foi implantado com um único objetivo: a produção de energia elétrica. Infelizmente a origem de problemas tão graves recaem em uma série de ações parciais equivocadas do passado, acumulando enganos, erros e omissões encadeadas de tal maneira que dificilmente oferecem uma saída sensata.

\section{A PAISAGEM POSSÍVEL}

Os fatos comentados aqui demonstram a face de certo ambientalismo voluntarioso e pragmático em voga no país. Há exceções, mas sempre a discussão que vem à tona, veiculada principalmente pela mídia, é o eterno confronto homem $x$ natureza, ainda com a "aura" maniqueísta da luta do bem contra o mal. Nesta linha de pensamento "...as qualidades intrínsecas das paisagens e espaços urbanos são relegados a um segundo plano, existindo posicionamentos que consideram tais estruturas altamente pemiciosas. Considera-se praticamente que a existência pura e simples da mata poderia e deveria garantir à sociedade instalada do outro lado, no espaço construído, uma excelente qualidade de vida"s.

A produção de novas configurações e paisagens por esta ideologia se conduz no sentido de tratar o meio ambiente humano como uma natureza domesticada. Padrões de desenho e projeto adquiridos na escala da cidade são transpostos para a macroescala por falta de domínio espacial e conceitual do problema. A referência projetual limita-se a dois modelos: a malha urbana 
convencional e a área de preservação intocada. A paisagem criada termina por ser a ilustração da pobreza dessa "crítica" que insiste em totens e chavões.

A discussão ambiental no Brasil cresceu muito e a legislação resultante foi um grande avanço. A preservação de um ecossistema natural não causa mais nenhuma estranheza à sociedade; passamos com sucesso pela fase de "catequismo" ecológico. Mas falta a continuidade: a prática do planejamento ambiental.

Não podemos nos furtar da idéia de que o planejador da paisagem é um dos mediadores entre os diversos segmentos da sociedade e seus respectivos interesses e desejos. Por outro lado, se a sociedade pede desse profissional respostas criativas, propostas alternativas, admite também uma crítica quanto à condução dos processos de urbanização. Há uma necessidade eminente de planejamento; os problemas aqui apresentados não decretam a falência do planejamento, pelo contrário, revelam sua importância.

A "onda ecológica" adotada pela mídia tem um efeito positivo no sentido de incutir nos cidadãos o sentimento de responsabilidade quanto à preservação da natureza, mas cabe aos órgãos governamentais esclarecer e informar sobre o que é a realidade ambiental e como manejá-la. Os órgãos de planejamento do Estado não são apenas fiscalizadores, mas promotores da educação ambiental, através da orientação técnica e da elaboração de material de divulgação de programas ambientais. Para isso, o governo deve adquirir o "know-how", através de uma prática de acompanhamento dos empreendimentos aprovados durante seu funcionamento, o que não tem acontecido atualmente.

A questão da educação ambiental é de extrema importância também na gestão dos conflitos entre sociedade e governo. As divergências entre as diversas posturas ideológicas e técnicas dos mais diferentes setores da sociedade são mediados hoje pela 
legislação. $O$ único fórum de debate é a audiência pública na ocasião do licenciamento de alguma atividade. Todo destaque é dado ao empreendimento, enquanto a discussão do planejamento ambiental na localidade onde este se encontra não ocorre. É plausível, portanto, que nessas oportunidades as discussōes extrapolem seus objetivos específicos e passem para tópicos mais gerais, resultando até em intermináveis discussões conceituais.

Este fato nos leva a pensar nas oportunidades perdidas para a discussão do próprio desenho da paisagem. Que cenários pretendemos?

Os estudos de impacto ambiental são atualmente uma das poucas ocasiões de "simulação" de paisagens possíveis. Desde a análise do sítio físico até a adequação do projeto às demandas sociais há a preocupação constante de construir um sistema passível de manutenção, tanto em termos técnicos como em termos sociais, ou seja, um sistema que ao mesmo tempo é sustentável e permite mudanças conforme novas necessidades.

O caso da represa Billings é típico: um projeto que foi idealizado para atender a um fim específico e que acabou arcando com demandas para as quais não estava preparado. Já com a rodovia Fernão Dias ocorreu o contrário. A previsão dos cenários compostos pelas alternativas de traçado orientou o projeto para a viabilização da melhor opção dentro do quadro analisado; este fato não foi levado em conta pelos opositores do EIA/RIMA. Mesmo a proposição de um projeto tão polêmico como a rodovia do Sol não inviabiliza uma discussão mais aprofundada da configuração desses cenários. Aliás, é exatamente o tipo de projeto a ser discutido nos próximos anos. A saturação do eixo São Paulo-Santos, tanto em termos estruturais como ambientais, requer alternativas, não necessitando estabelecer, entretanto, a criação de novos eixos rodoviários, novos pólos turísticos e portuários. 
Quando nos confrontamos com os problemas mencionados neste texto, percebemos o quanto precisamos crescer, principalmente em termos políticos. Todo o avanço técnico adquirido nos últimos anos é desperdiçado quando não temos um projeto econômico e social claro, atrelado a um projeto político.

Sabemos hoje que a natureza como paraíso intocado não existe e a única forma de garantirmos a qualidade de vida, tal como a concebemos atualmente, para futuras gerações é admitir o meio ambiente alterado e modificado pelo homem. Há uma interdependência entre homem e meio, não são agentes autônomos. Portanto, a melhor forma de preservação de áreas protegidas por lei, tão próximas de centros urbanos como acontece no Estado de São Paulo, é tornando-as acessíveis à sociedade, para que ela se torne $o$ agente fiscalizador de atos indesejáveis, como poluição de mananciais, derrubada de mata, caça a animais selvagens, etc.

Este é um apelo no sentido "ecológico" bastante coerente. No outro sentido, ou seja, do ponto de vista humano, trata-se de exercer um certo domínio sobre a natureza para a conservação de recursos, garantindo a manutenção dos modos de produção e da tecnologia dos quais o homem depende.

A postura de projeto deve ser a de buscar as identidades (cultural, paisagística, ambiental) de cada lugar, e não novos modelos. A pergunta não é "Qual o meu modelo de urbanização para este lugar?" e sim "Quais as características de urbanização que este lugar sugere?" O modelo é único, e por isso mesmo restrito. Invertendo este modo de produção trabaIhando a partir do lugar, e não do desenho, vislumbramos muito mais possibilidades de configuração. $\mathrm{O}$ "re-arranjo" do território parte então de um processo de projeto-produto mais interativo, se admitirmos essa "interferência" da realidade sobre o idealizado. 


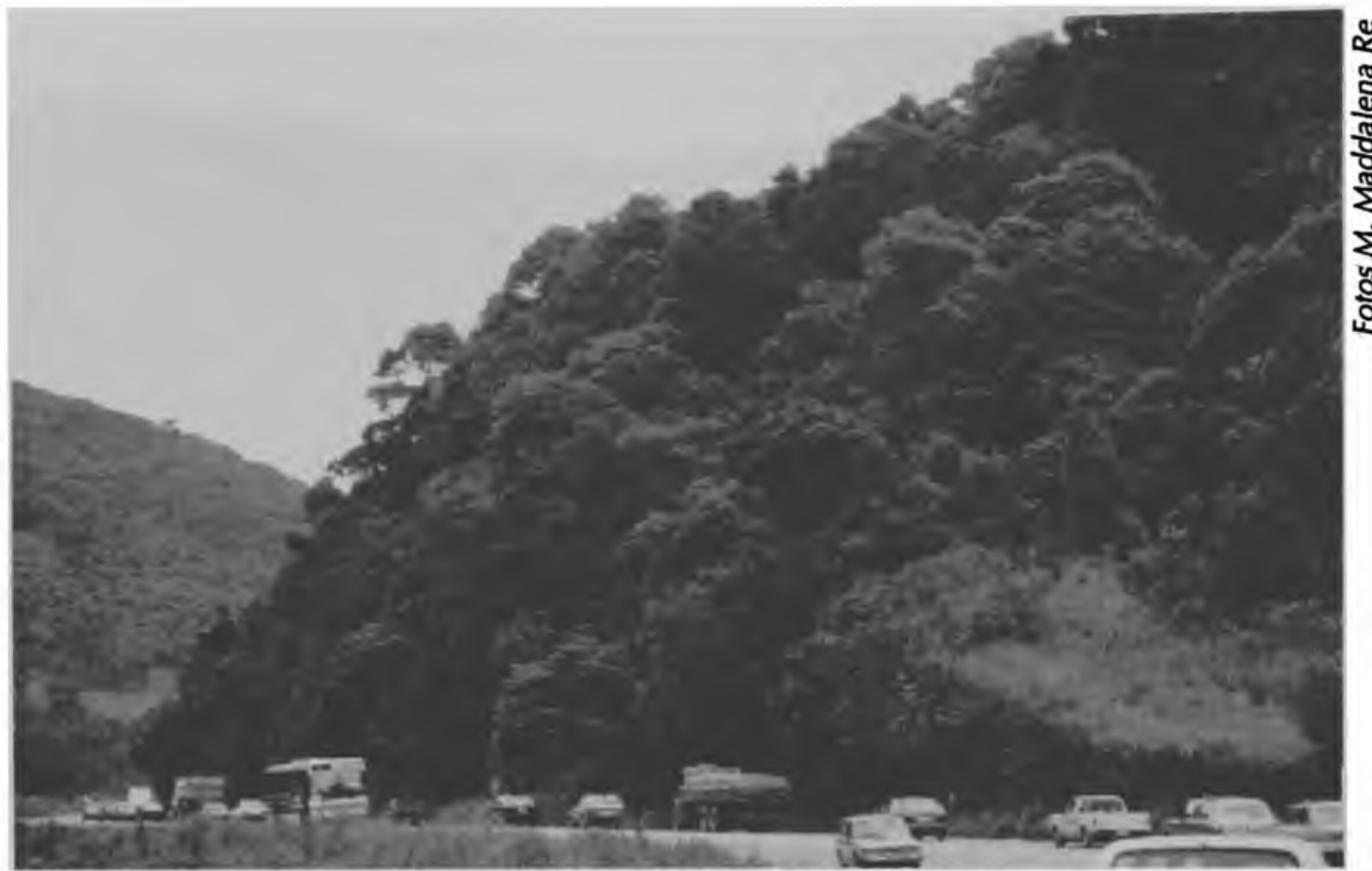

Estrada no km 70, próximo ao Túnel da Mata Fria (túnel sob a Serra da Cantareira). Tráfego intenso e pista sem acostamento geram congestionamentos neste trecho, justificando sua ampliação.

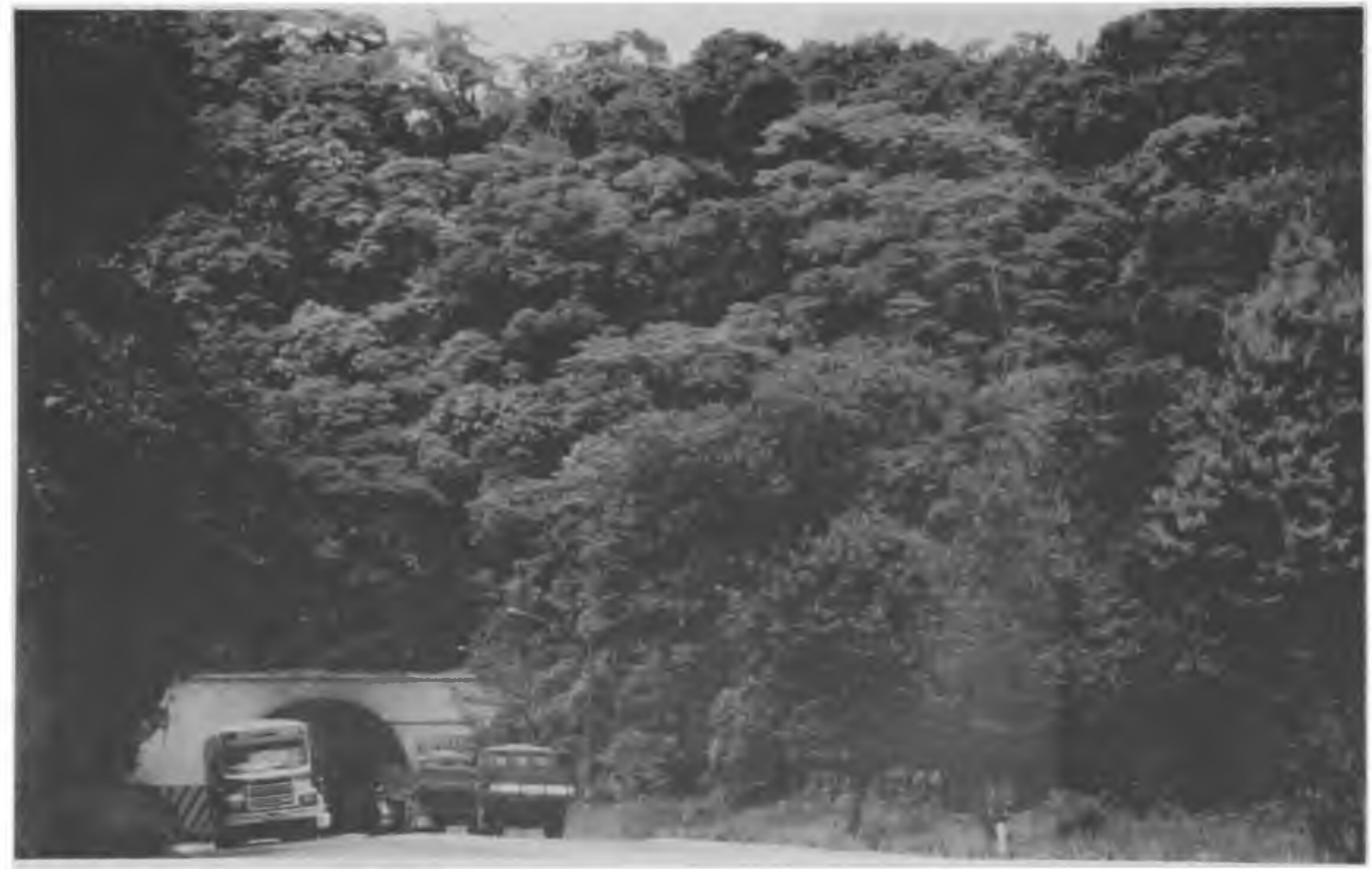

Túnel da Mata Fria, a serduplicado à direita da pista existente. Área de maior impacto na vegetação durante as obras, onde cuidados especiais no projeto da estrada são necessários para a recomposição da mata. 

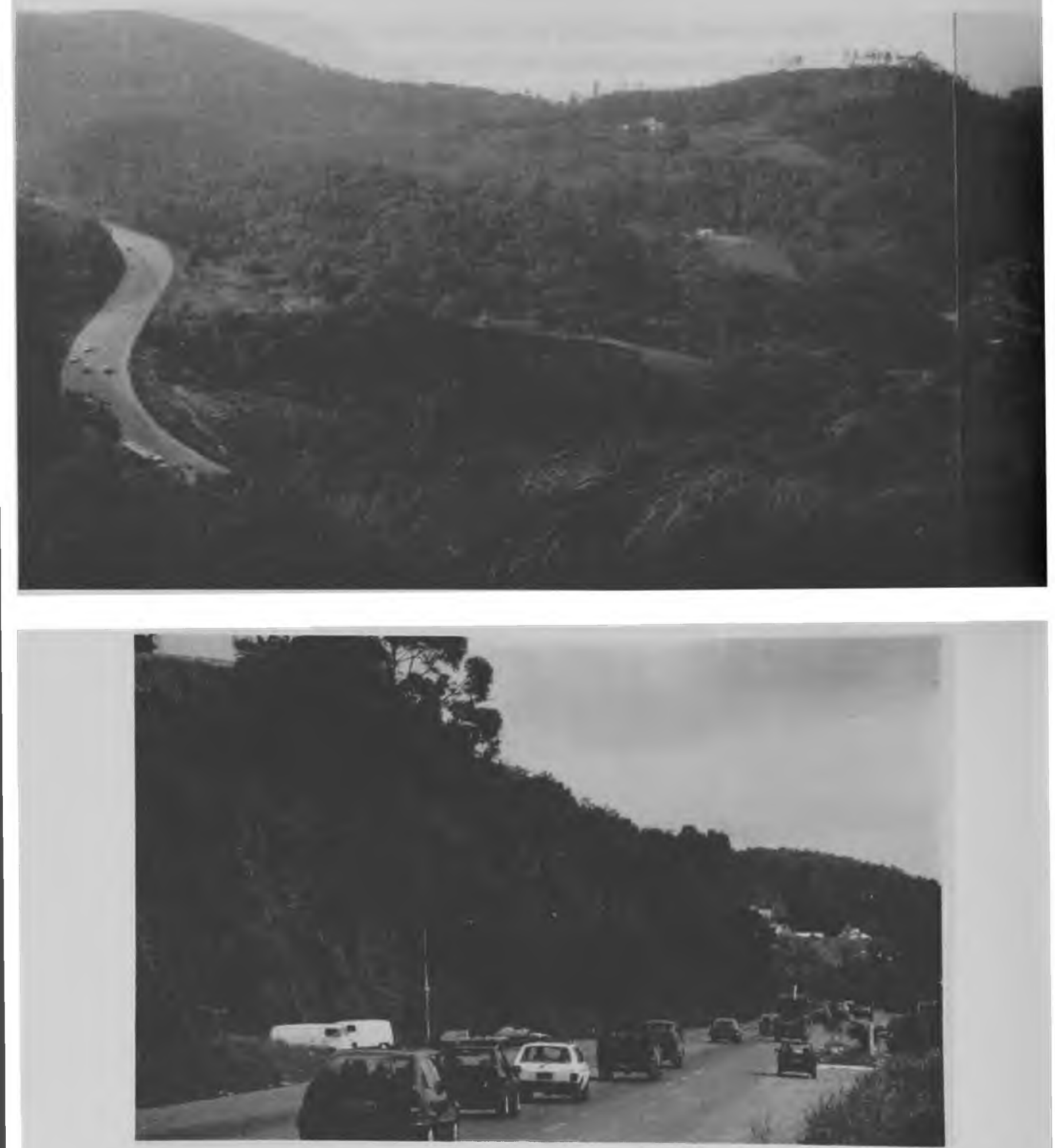

Intersecçåo com a rodovia $S P 88$, no km 80 . Observa-se aqui a extrema falta de segurança na travessia, tanto pelo tráfego intenso, como pelas condiçzes precárias de visibilidade, o que exigirá remodelação total do traçado. 
Vista de trecho da estrada, entre os $\mathrm{km} 59$ e 61, a partirdo morro do Juqueri. Consiste em área de proteção aos mananciais, coberta parcialmenteporvegetaçãonativa e em sua maior parte ocupada por pastagens e reflorestamentos.

\section{NOTAS}

(1) LEITE, M. A. F. , 1992, p. 1.

(2) VIOLA, E. J., 1991.

(3) GONÇALVES, W., 1992, p. 189-195.

(4) CONAMA, Resolução 001/86.

(5) SEMA, 1986.

(6) SILVA, C. C. A, 1990, 181-182.

(7) "Prós e contras da rodovia do Sol", 1989.

(8) MACEDO, S. S., 1993., p. 16. 


\section{BIBLIOGRAFIA}

CHACUR, Helena Napoleon D. Paisagem e proteção ambiental: algumas reflexões sobre conceitos, desenho e gestão do espaço. In: Paisagem e Ambiente - Ensaios IV. São Paulo: FAUUSP, 1992.

FOLHA DE S. PAULO. Passeata 'verde' pede Billings sem poluição. São Paulo, 10 de jul. de 1993. jul. de 1993.

GONÇALVES, Wantuelfer. Florestas: objeto ou instrumento de preservação? In: Paisagem e Ambiente - Ensaios IV. São Paulo: FAUUSP, 1992.

LEITE, Maria Angela F.P. Novos valores: destruição ou desconstrução? São Paulo, 1992. Tese (Doutorado) Faculdade de Arquitetura e Urbanismo, Universidade de São Paulo.

MACEDO, Sílvio S. Paisagem, urbanização e litoral: do Éden à cidade. São Paulo, 1993. Tese (Livre-docência) - Faculdade de Arquitetura e Urbanismo, Universidade de São Paulo.

MADDALENA RE. Paisagismo. Estudo de impacto ambiental da rodovia Fernão Dias. São Paulo, 1993.

PEDRETTI, Luiz José. Grande São Paulo: aspectos jurídicos. In: Revista do SPAM, n.15. São Paulo, SNM/EMPLASA, 1985. p.28-31.

REVISTA OBRA, PROJETO EDITORES. Prós e contras da rodovia do Sol, maio de 1989.

ROCHA, Aristides A. Do lendário Anhembi ao poluído Tietê. São Paulo: EDUSP, 1991.

SÃO PAULO (Estado) Estudo de Impacto Ambiental-EIA. Relatório de Impacto Ambiental-RIMA: manual de orientação. São Paulo: Secretaria do Meio Ambiente, 1989. 
SILVA, Carlos Celso A. Meio ambiente e desenvolvimento urbano e regional. In: SãoPauloMetrópole: planejamento egestão. Seminário Internacional. São Paulo, SEP/SHDU/EMPLASA, 1990. p.179-186.

VIOLA, Eduardo J. A problemática ambiental no Brasil (1971-1991): da proteção ambiental ao desenvolvimento sustentável. In: Ambiente urbano e qualidade de vida. São Paulo: Publicações Polis, n. 3, 1991. p.4-14. 